\title{
PENERAPAN METODE FORWARD CHAINING UNTUK DIAGNOSA PENYAKIT DIARE PADA ANAK USIA 3-5 TAHUN BERBASIS MOBILE ANDROID
}

\author{
Joko Trianto \\ Teknik Informatika, Universitas Pamulang \\ JL. Surya Kencana No. 1, Pamulang, Tangerang Selatan-Indonesia \\ email :dosen00355@unpam.ac.id
}

\begin{abstract}
Penyakit diare merupakan salah satu masalah kesehatan masyarakat yang utama di Indonesia, khususnya yang terjadi pada anak dibawah lima tahun. Hal ini disebabkan karena, masih kurangnya pengetahuan pada sebagian orang tua balita mengenai penanganan seperti apa yang harus dilakukan pada penyakit yang timbul, serta kurangnya kesadaran orang tua balita untuk berperilaku hidup bersih dan sehat. Selain itu, sulitnya para orang tua balita dalam mencari solusi penanganan penyakit yang tepat pada situasi yang kurang mendukung. Melihat kondisi seperti itu, maka dibuatlah sebuah sistem untuk diagnosa penyakit diare yang digunakan untuk menunjang pelayanan kesehatan terhadap anak khususnya balita. Dalam penelitian ini,metode yang digunakan dalam pembuatan sistem ini yaitu dengan menggunakan metode Forward Chaining (Pelacakan Runut Maju), dengan teknik penelusuran Best First Search. Hasil dari penelitian ini diharapkan dapat berfungsi dengan optimal untuk kasus penyakit diare yang terjadi pada seorang balita, dimana tidak memerlukan interaksi antara dokter dan pasiennya secara langsung.
\end{abstract}

Kata kunci : Forward Chaining, Diagnosa, Diare, Android

\section{LATAR BELAKANG}

Penyakit diare masih merupakan salah satu masalah kesehatan masyarakat yang utama di Indonesia, ini ditunjukkan dengan tingginya angka kesakitan dan kematian yang disebabkan oleh penyakit tersebut, khususnya yang terjadi pada anak dibawah lima tahun. Karena saat usia anak dibawah lima tahun, sistem kekebalan tubuh yang terbentuk belum sempurna. Akibatnya, anak bisa dengan mudah terserang penyakit.

Menurut Depkes tahun 2015, diare merupakan penyakit endemis di Indonesia dan juga merupakan penyakit potensial kejadian luar biasa yang sering disertai dengan kematian. Hasil riskesdas (riset kesehatan dasar) tahun 2007 menyatakan bahwa diare merupakan penyebab kematian nomor satu pada bayi $(31,4 \%)$ dan pada balita $(25,2 \%)$, sedangkan pada golongan semua umur merupakan penyebab kematian yang ke-empat $(13,2 \%)$. Pada tahun 2012 angka kesakitan diare pada semua umur sebesar 214 per 1.000 penduduk dan angka kesakitan diare pada balita 900 per 1.000 penduduk (Kajian Morbiditas Diare 2012). Menurut riskesdas tahun 2007, bila dilihat secara per kelompok, umur diare tersebar di semua kelompok umur dengan prevalensi tertinggi terdeteksi pada anak balita (1-4 tahun) yaitu 16,7\%. Sedangkan menurut jenis kelamin prevalensi laki-laki dan perempuan hampir sama, yaitu $8,9 \%$ pada laki-laki dan $9,1 \%$ pada perempuan.

Ada hubungan negatif antara kejadian diare dengan tingkat pengetahuan orang tua dan indeks kekayaan kuantil. Semakin tinggi pengetahuan orang tua balita akan gejala penyakit dan solusi pada penyakit tersebut, maka semakin rendah tingkat prevalensi diare. Akan tetapi pada kenyataannya, masih kurangnya pengetahuan pada sebagian orang tua balita mengenai penanganan seperti apa yang harus dilakukan pada penyakit yang timbul, serta kurangnya kesadaran orang tua balita untuk berperilaku hidup bersih dan sehat. Selain itu, sulitnya para orang tua balita dalam mencari solusi penanganan penyakit yang tepat pada situasi yang kurang mendukung.

Melihat kondisi seperti itu, penulis mencoba untuk membuat sebuah sistem yang digunakan untuk menunjang pelayanan kesehatan terhadap anak khususnya balita. Karena diperlukan adanya pengetahuan mengenai penyakit yang dialami oleh si anak 
agar mengetahui dengan pasti penyakit apa yang diderita dan kemudian tindakan apa yang harus segera dilakukan. Lebih jelas lagi penyakit diare pada anak perlu diketahui gejala serta tindakan pertama apa yang perlu dilakukan oleh para orangtua balita maupun seorang petugas kesehatan. Karena bila penanganannya tidak tepat, dapat berakibat fatal.

Sistem ini akan mengadopsi cara kerja seorang dokter dalam mendiagnosa penyakit seorang pasien dan akan sedapat mungkin memberikan penjelasan mengenai penyakit tersebut serta pengobatan pertama atau disebut sebagai swamedikasi yang dianjurkan kepada seorang pasien untuk mengobati penyakitnya. Swamedikasi adalah pemilihan dan penggunaan obat modern, herbal, maupun obat tradisional oleh seorang individu untuk mengatasi penyakit atau gejala penyakit (WHO, 1998).

Sistem ini akan membandingkan gejala atau symptom yang diderita oleh seorang pasien dengan sebuah data tentang penyakit beserta gejalanya. Kemudian hasil dari perbandingan tersebut akan diambil yang memiliki tingkat ketepatan yang paling tinggi. Sehingga telah diketahui diagnosa tentang penyakit seorang pasien sehingga dapat diketahui pula penanganan yang tepat untuk mencegah terjadinya gejala penyakit lebih lanjut. Sistem ini dibuat berdasarkan hasil riset penelitian yang telah dilakukan oleh penulis secara langsung kepada Dr. Rachmat Kurniawan, Sp. A. M. Kes sebagai dokter spesialis anak di Mayapada Hospital Tangerang.

Namun demikian, tentunya sistem ini tidak akan serta merta menggantikan peran kerja seorang dokter secara keseluruhan. Sistem ini dapat berfungsi dengan optimal untuk kasus penyakit diare yang terjadi pada seorang balita, dimana tidak memerlukan interaksi antara dokter dan pasiennya secara langsung.

\section{METODE PENELITIAN}

Sistem ini hanya digunakan untuk prosedur penanganan penyakit pada anak balita yang menderita penyakit diare. Data sampel sebagai data jenis penyakit yang terdiagnosa beserta pelaksanaan pertamanya adalah sebagai berikut :

\section{Analisis Metode Pelacakan}

Metode pelacakan yang digunakan dalam membangun sistem untuk diagnosa penyakit diare pada balita adalah forward chaining. Dengan menggunakan metode ini, semua data gejala dan aturan akan ditelusuri utnuk mendapatkan hasil diagnosa penyakit yang terdeteksi.

\section{Analisis Metode Pencarian}

Metode pencarian yang digunakan dalam membangun sistem untuk diagnosa penyakit diare pada balita adalah best first search. Proses pencarian ini memeriksa semua simpul tujuan (jenis penyakit). Metode ini digunakan agar proses pencarian lebih efektif, menemukan solusi terbaik tanpa harus menguji lebih banyak lagi dalam ruang keadaan.

\section{Analisis Pohon Keputusan}

Pembentukan pohon keputusan pada sistem pakar untuk diagnosa penyakit diare menggunakan binary tree. Pohon keputusan ini dikombinasikan dengan metode pencarian best first search, yang dapat dilihat pada gambar dibawah ini.

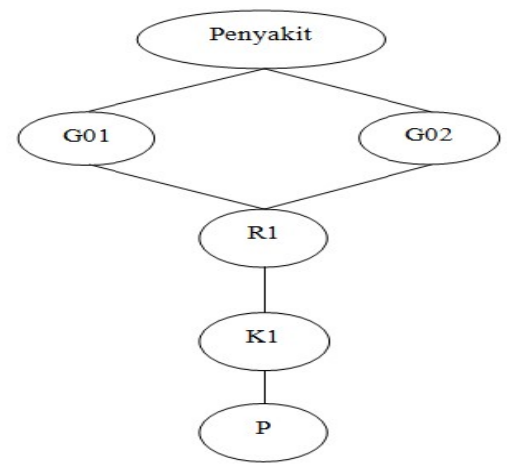

Gambar 3. 1 Pohon Keputusan Best First Search

Keterangan :

$\mathrm{G}$ : Jenis-jenis gejala

$\mathrm{R}$ : Kelompok Gejala

$\mathrm{K}$ : Penyakit

$\mathrm{P}$ : Kesimpulan

\section{Perancangan Pohon Keputusan Diagnosa Penyakit Diare}

Diagram pohon keputusan adalah suatu rancangan yang digunakan untuk membangun sistem pakar, diagram pohon keputusan akan mempermudah untuk menyusun basis 
pengetahuan dan aturan serta menentukan faktor kepastian dari diagnosa penyakit diare.

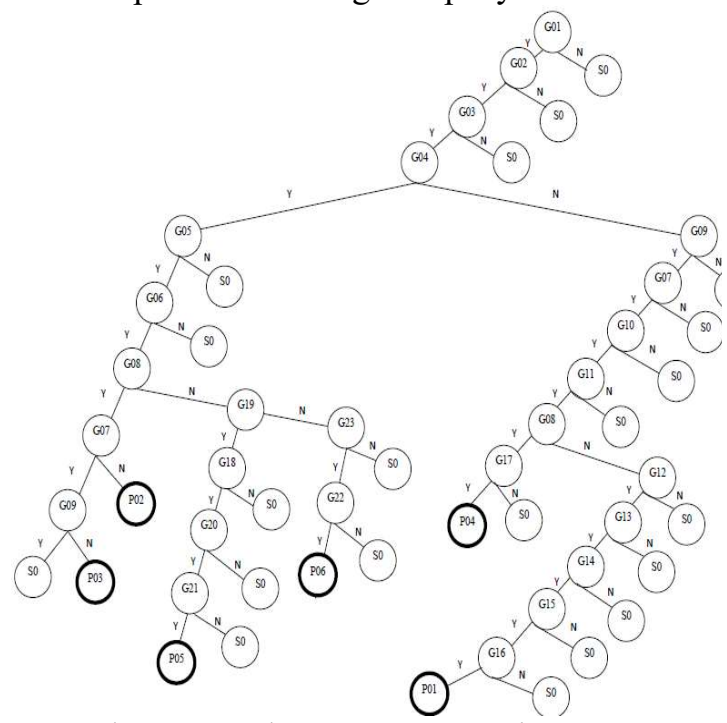

Gambar 3. 2 Pohon Keputusan Diagnosa Diare

\section{Analisis Kaidah Produksi}

Kaidah produksi biasanya dituliskan dalam bentuk jika-maka (IF-THEN). Kaidah ini dapat dikatakan sebagai hubungan implikasi dua bagian, yaitu bagian premise (jika) dan bagian konklusi (maka). Apabila bagian premise dipenuhi, maka bagian konklusi juga akan bernilai benar. Sebuah kaidah terdiri dari klausa-klausa. Sebuah klausa mirip sebuah kalimat subyek, kata kerja dan objek yang menyatakan suatu fakta. Ada sebuah klausa premise dan klausa konklusi pada sebuah kaidah. Suatu kaidah juga terdiri atas beberapa premise dan lebih dari satu konklusi. Antara premise dan konklusi dapat berhubungan dengan "OR" atau " $A N D$ ". Berikut kaidah-kaidah produksi dalam menganalisis penyakit diare :

\section{a. Model Use Case Diagram}

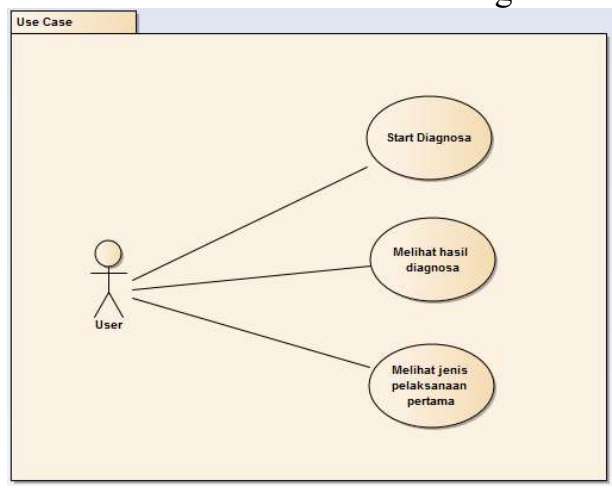

Gambar 3. 3 Use Case Diagram Sistem Diagnosa Penyakit Diare

\section{Activity Diagram}

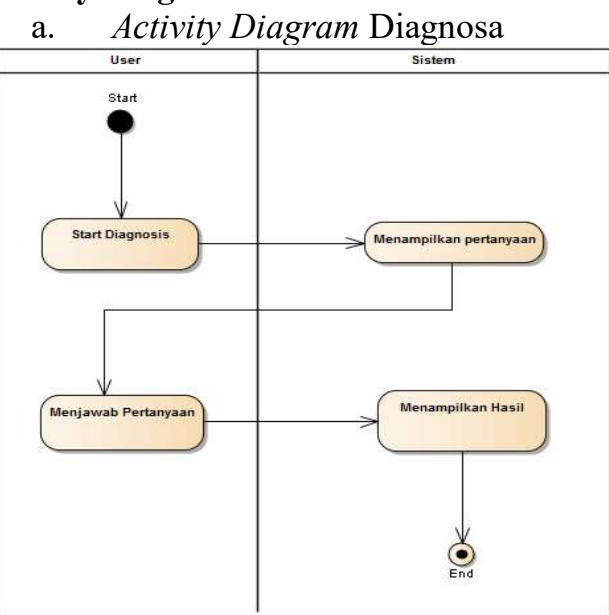

Gambar 3. 4 Activity Diagram Diagnosis

Pada gambar 3.4 menggambarkan kegiatan user dimana user melakukan diagnosis dengan menjawab pertanyaanpertanyaan yang dikeluarkan oleh sistem. Jika jawaban atau gejala yang dialami sesuai dengan rule atau aturan yang telah ada pada sistem, maka sistem akan menampilkan hasil diagnosis penyakit yang diderita.

b. Activity Diagram Pelaksanaan Pertama

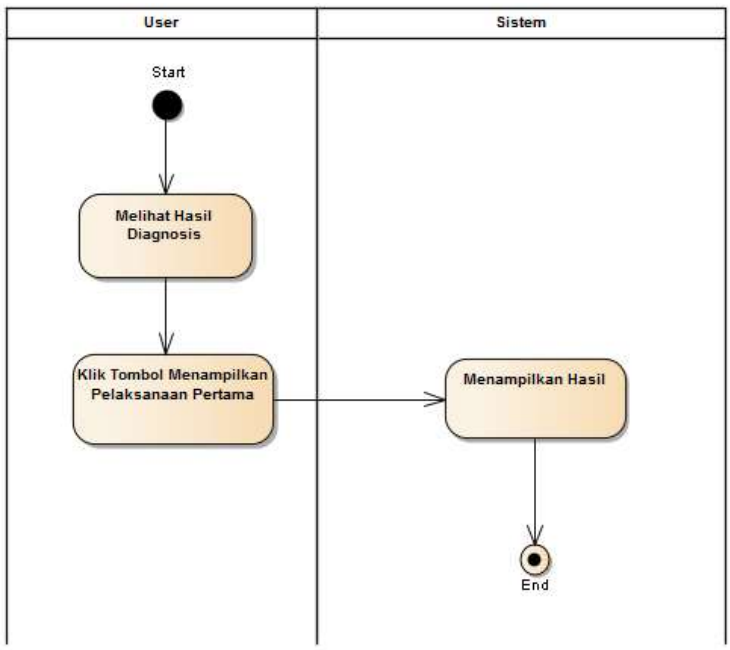

Gambar 3. 5 Activity Diagram Pelaksanaan Pertama

Pada gambar 3.5 menggambarkan kegiatan user yang ingin melihat jenis pelaksanaan pertama dari hasil diagnosis. 
Setelah hasil diagnosis muncul pada sistem, user memilih tombol untuk menampilkan jenis pelaksanaan pertama berdasarkan hasil diagnosis.

\section{Sequence Diagram}

Pada diagram sekuensial atau sequence diagram ini akan menggambarkan perilaku aktor dengan objek yang berkaitan serta message (pesan) yang akan disampaikan. Sequence diagram pada sistem diagnosa penyakit diare pada balita diantaranya sebagai berikut :

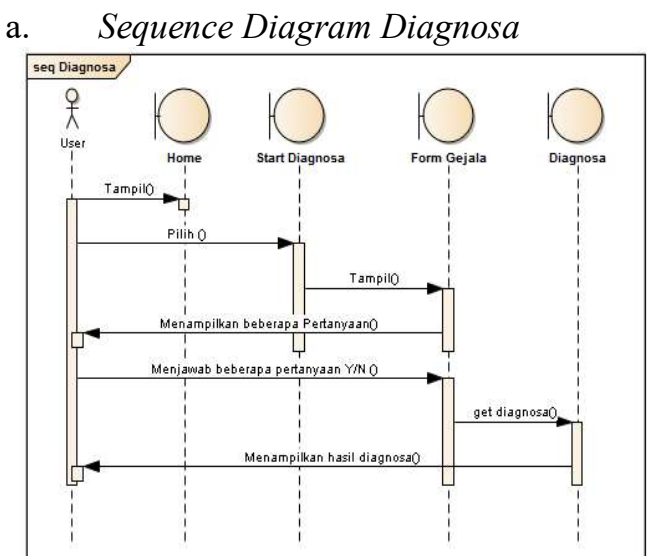

Gambar 3. 6 Sequence Diagram Diagnosa

b. Sequence Diagram Pelaksanaan pertama

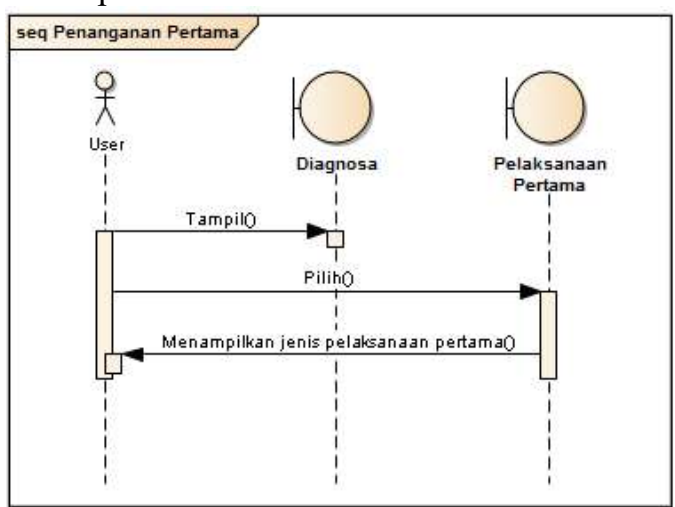

Gambar 3. 7 Sequence Diagram Pelaksanaan Pertama

\section{Perancangan Antar Muka Pengguna (User Interface)}

Perancangan antar muka pengguna (user interface) bertujuan untuk memberikan gambaran tentang aplikasi yang akan dibangun. Sehingga akan mempermudah dalam mengimplementasikan aplikasi. Desain antar muka pengguna pada sistem diagnosa penyakit diare pada balita ini dibuat sebagai berikut :

a. Halaman Menu Utama

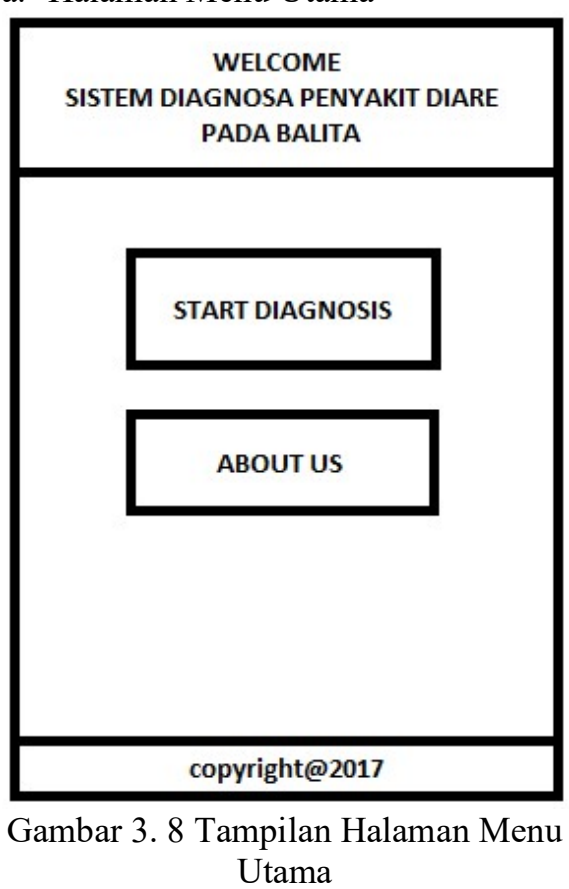

b. Halaman Diagnosis Penyakit

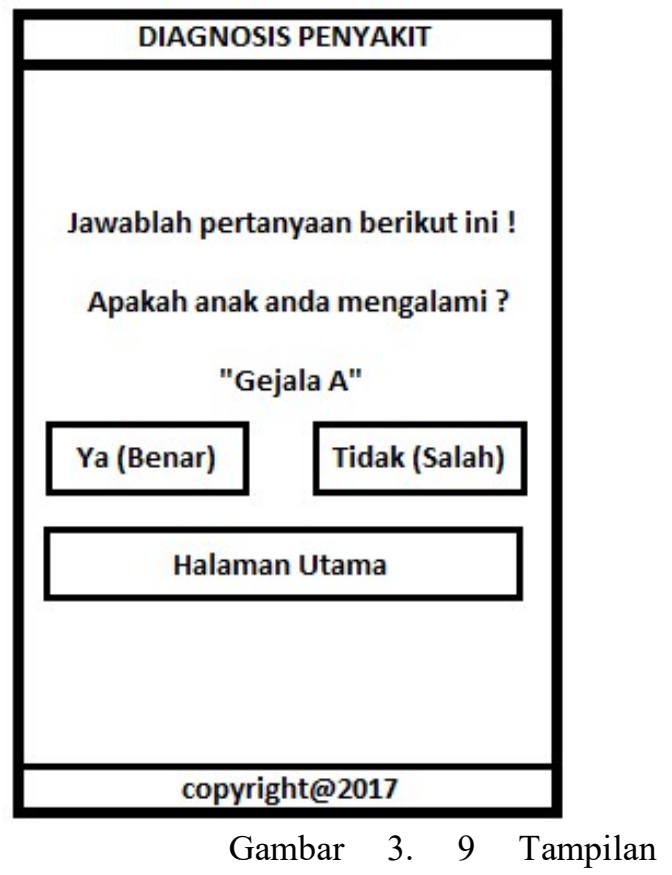

Halaman Diagnosis Penyakit

c. Halaman Hasil Diagnosis 


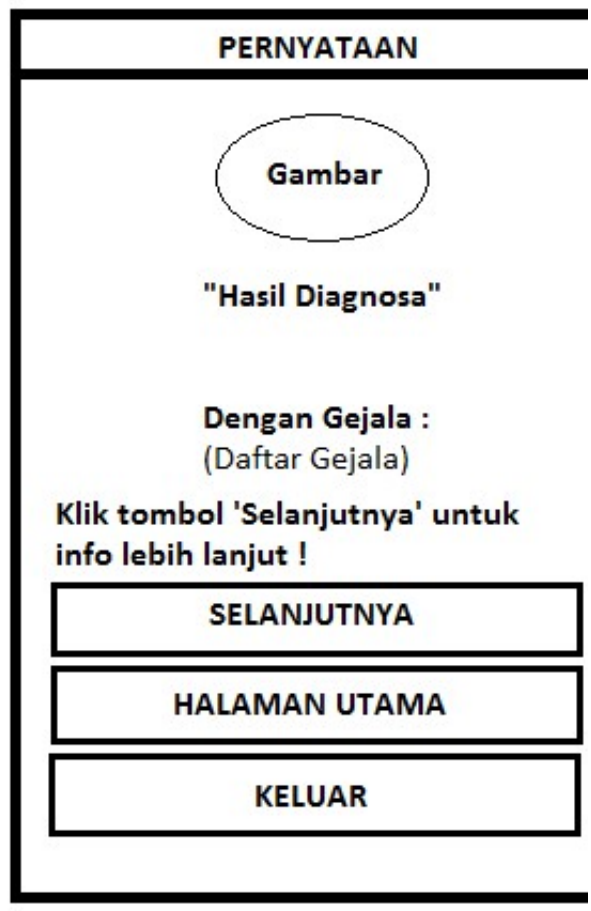

Gambar 3. 10 Tampilan Halaman Hasil Diagnosis

d. Halaman Pelaksanaan Pertama

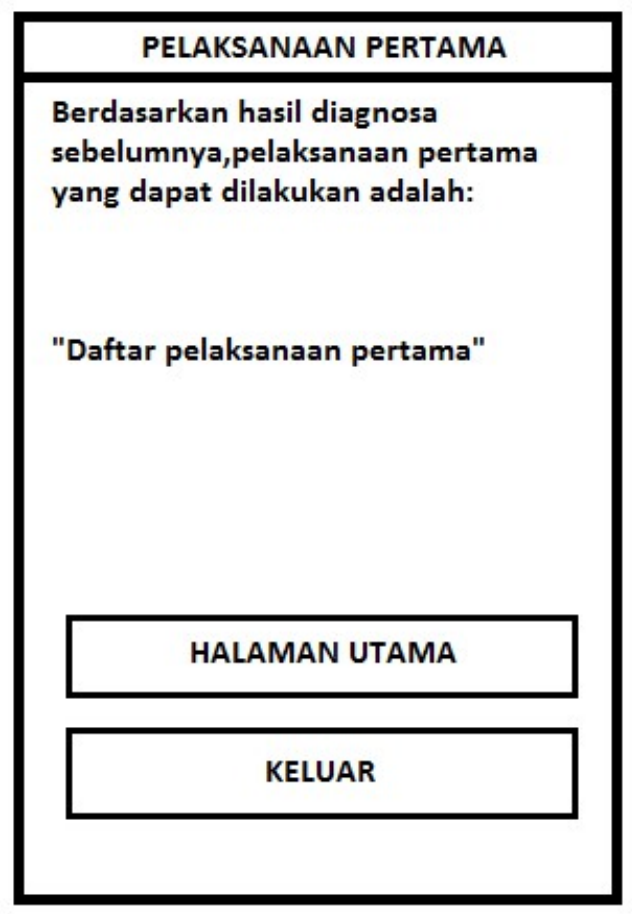

Gambar 3. 11 Tampilan Halaman Pelaksanaan Pertama

e. Halaman About Us

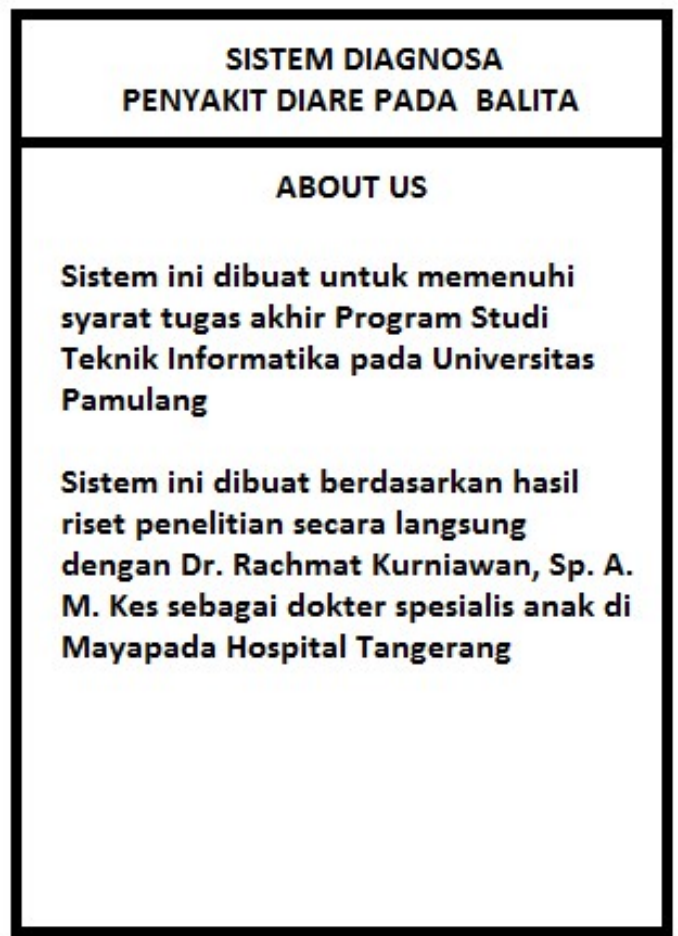

Gambar 3. 12 Tampilan Halaman About Us

\section{KESIMPULAN}

Dalam penulisan skripsi ini penulis telah uraikan bagaimana perancangan dan pengimplementasian sebuah sistem diagnosa penyakit diare pada anak usia 3-5 tahun berbasis mobile android pada Mayapada Hospital. Maka dapat penulis simpulkan sebagai berikut:

1. Aplikasi berbasis mobile android dapat menjadi alternatif pilihan utama bagi pengguna dalam mencari informasi mengenai diagnosa suatu penyakit diare pada anak usia 3-5 tahun, sesuai dengan hasil pada lembar angket kuesioner sebanyak 10 lembar yaitu dikarenakan aplikasi ini mudah dalam penggunaannya.

2. Aplikasi ini mudah diakses oleh para pengguna karena beroperasi secara offline tanpa jaringan data.

3. Dengan menggunakan aplikasi sistem diagnosa penyakit diare ini, para pengguna khususnya orang tua dapat dengan mudah memperoleh informasi penanganan pertama yang harus dilakukan terkait dengan hasil diagnosa. 


\section{SARAN}

Berdasarkan kesimpulan yang telah dibuat maka saran yang akan disampaikan penulis untuk meningkatkan sistem yang dirancang untuk kebutuhan yang akan mendatang adalah sebagai berikut:

1. Tampilan sistem aplikasi yang dibuat masih sederhana, untuk penelitian selanjutnya diharapkan sistem yang dirancang dan dibuat dapat menyempurnakan penelitian sebelumnya agar dapat menghasilkan tampilan yang lebih menarik dan inovatif.

2. Sistem aplikasi yang dibuat belum cukup akurat dalam mendiagnosa penyakit diare, untuk penelitian selanjutnya sistem diharapkan dapat dikembangkan lagi untuk menghasilkan hasil diagnosa yang lebih akurat dibandingkan penelitian sebelumnya.

3. Pembuatan sistem aplikasi ini masih beroperasi secara offline, sebaiknya pengembangan kedepannya dapat beroperasi secara online.

\section{DAFTAR PUSTAKA}

Merlina, Nita., dan Hidayat, Rahmat. 2012. Perancangan Sistem Pakar. Jakarta: Ghalia Indonesia.

Arhami, Muhammad. 2005. Konsep Dasar Sistem Pakar. Yogyakarta: Andi.

S, Rosa A., dan Shalahuddin, M.. 2016. Rekayasa Perangkat Lunak Terstruktur dan Berorientasi Objek. Bandung: Informatika.

Suarga. 2009. Dasar Pemrograman Komputer dalam Bahasa Java. Yogyakarta: Andi.

Jadiaman P., Viktor H. P., \& Dwimaryuga P.. (2012). Sistem Pakar Diagnosa Penyakit Jantung Menggunakan Metode Certainty Factor Berbasis Web. Universitas Palangkaraya.

Fitri N., Yoga H. A., \& Endah N. Y.. (2016). Aplikasi Pakar untuk Diagnosa Penyakit Kulit Menggunakan Metode Forward Chaining di Al Arif Skin Care Kabupaten Ciamis. STMIK Tasikmalaya.

Dadi R., dan Asril H.. (2014). Sistem Pakar Diagnosa Penyakit Tanaman Padi Menggunakan Metode Forward Chaining. STMIK Mardira Indonesia. Vol.8 . No 1: 43-48.

Kementrian Kesehatan RI. (2014). Profil Kesehatan Indonesia Tahun 2014. Kementrian Kesehatan RI.
Kementrian Kesehatan RI. (2015). Profil Kesehatan Indonesia Tahun 2015. Kementrian Kesehatan RI.

Kementrian Kesehatan RI. (2011). Situasi

Diare di Indonesia. Kementrian Kesehatan RI. 